\title{
Genes involved in glucose repression and oxidative stress response in the fission yeast Schizosaccharomyces pombe
}

\author{
K.G. Suslu, B. Palabiyik and G. Temizkan \\ Department of Molecular Biology and Genetics, Faculty of Science, \\ Istanbul University, Istanbul, Turkey \\ Corresponding author: B. Palabiyik \\ E-mail: bediag@istanbul.edu.tr
}

Genet. Mol. Res. 10 (4): 4041-4047 (2011)

Received October 13, 2011

Accepted October 27, 2011

Published November 8, 2011

DOI http://dx.doi.org/10.4238/2011.November.8.4

\begin{abstract}
We looked for changes in gene expression and novel genes that could be involved in the interaction between glucose repression and oxidative stress response in the fission yeast, Schizosaccharomyces pombe, using a constitutive invertase mutant, ird11, which is resistant to glucose. BLAST analysis was made of the $S$. pombe genome database of cDNAs whose expression ratios differentially decreased or increased upon exposure to mild oxidative stress in this mutant compared to the wild type. Genes with this type of activity were identified as rpl302, encoding $60 \mathrm{~S}$ ribosomal protein L3, and mpgl, encoding mannose-1-phosphate guanyltransferase; their expression patterns were measured using quantitative real-time PCR. We found that the expression levels of rpl302 and mpgl genes in ird 11 under unstressed conditions were increased compared to those of the wild type. Under stress conditions, the expression levels of the rpl302 gene were decreased in both strains, while mpgl expression levels remained unchanged. These results suggest that these genes play a role in the response to oxidative stress in this mutant strain.
\end{abstract}

Key words: Schizosaccharomyces pombe; Glucose signalling; Oxidative stress response; Glucose repression; Differential display 


\section{INTRODUCTION}

Glucose is the most preferred and efficient carbon and energy source for almost all organisms. This simple sugar also regulates, via glucose sensing and signaling, a variety of metabolic pathways such as the respiratory pathway, stress response element and glycolysis enzymes for utilization of alternative carbon sources, glucose transporters, etc., resulting in opportunities to act as a metabolic intermediate, cofactor and end-product (Voet et al., 1999; Johnston, 1999; Flores et al., 2000; Rolland et al., 2001).

Eukaryotic organisms have myriad complex strategies for responding and regulating glucose sensing and signaling pathways. Studies for revealing these mechanisms have been done extensively in budding yeast Saccharomyces cerevisiae, one of the most important eukaryotic model organisms (Rolland et al., 2001; Gancedo, 2008). Another yeast Schizosaccharomyces pombe, which has shown significant similarities withmammalian cells in terms of features at the genetic, biochemical and molecular level (Schmidt et al., 2007), is also commonly used for studies focusing on glucose metabolism (Lin et al., 2000; Janoo et al., 2001; Roux et al., 2009) and oxidative stress response (Toone et al., 2001; Chen et al., 2003, 2008; Ikner and Shiozaki, 2005).

Glucose is primarily detected by membrane receptors ( $\mathrm{G}$ protein-coupled receptors; GPCRs) and generates a signal via the cAMP-dependent protein kinase A (PKA) signal pathway in S. pombe. (Welton and Hoffmann, 2000; Hoffman, 2005). It is known that glucose depletion or respiratory growth on a non-fermentable carbon source leads to increased oxidative stress response in S. pombe (Moradas-Ferreira et al., 1996; Quinn et al., 2002; Chen et al., 2003; Madrid et al., 2004; Kim et al. 2006). The central element of the mitogen-activated protein kinase (MAPK) cascade directing the transcriptional response to oxidative stress in this fission yeast is MAPK Sty1, and this protein kinase activates the transcription factors Atflp and Pap $1 \mathrm{p}$ (Ikner and Shiozaki, 2005). Additionally, glucose sensing and signaling regulates the increased expression of various stress response genes through the activation of the Atflp and Pap $1 p$ transcription factors in S. pombe (Madrid et al., 2004; Stiefel et al., 2004). The activation of a Sty1 MAP kinase by calorie restriction participates in life span extension, which was shown for the first time by Zuin et al., (2010). In the same study, it was reported that either low-glucose media or activation of the nutrient-dependent Pkal pathway promoted life span extension in fission yeast, including high respiratory rates, elevated ROS production, activation of the MAP kinase Sty1 pathway and expression of survival genes.

Although there is a wide range of studies supporting the relationship between glucose repression and oxidative stress in $S$. pombe, it is not fully understood how this relationship takes place and which molecules play crucial roles in this process. We aimed to investigate the relationship between each major step of glucose metabolism and its related effect on oxidative stress response using a constitutive invertase mutant resistant to glucose repression (ird11) (Kig et al., 2005). This mutant, ird11, seems to be affected by glucose signaling in a different manner than that caused by glucose deprivation (Palabiyik et al., in press).

In this study, the genes responsible for resistance to oxidative stress in the mutant compared to wild-type were determined by employing the differential display technique. The characterization of each potential gene representing differentially expressed cDNA fragments was implemented by scanning the $S$. pombe genome database, and two genes were identified: $r p l 302$, encoding 60S ribosomal protein L3, and $m p g 1$, encoding mannose-1-phosphate guanyltransferase. Differential expression patterns of these genes were confirmed by quantitative real-time PCR. 


\section{MATERIAL AND METHODS}

\section{Yeast strains and growth media}

The S. pombe Lindner liquifaciens strains wild-type (972 $h^{-}$) and a constitutive invertase mutant resistant to glucose repression (ird 11 h) (Kig et al., 2005) were used. Selective medium for the $\operatorname{ird} 11$ mutant ( $0.5 \%$ yeast extract, $3 \%$ sucrose and $400 \mu \mathrm{g} / \mathrm{mL} 2$-deoxy-D-glucose; Rincon et al., 2001) and standard rich yeast extract medium (YEL and YEA; Gutz et al., 1974) were used for cultivation.

\section{Hydrogen peroxide treatment of $S$. pombe cells}

Exponentially growing $S$. pombe cells (ird11 and wild-type) were split into two tubes. In one of them, as the experimental group, the medium contained a mild level of hydrogen peroxide (Sigma, H1009) ( $2 \mathrm{mM} \mathrm{H}_{2} \mathrm{O}_{2}$, exposure for $1 \mathrm{~h}$ ) as described by Pekmez et al. (2008). The other group had no added $\mathrm{H}_{2} \mathrm{O}_{2}$ (control group). At the end of treatment, both experimental and control cells were harvested by centrifugation and washed with sterile distilled water.

\section{Differential expression analysis}

$\mathrm{H}_{2} \mathrm{O}_{2}$-induced changes in gene expression in $\mathrm{ird} 11$ and wild-type were investigated using the differential display technique, originally developed by Liang and Pardee (1992).

\section{RNA isolation and cDNA synthesis}

Total RNA was isolated from $\mathrm{H}_{2} \mathrm{O}_{2}$-treated and untreatedcells, using the High Pure RNA Isolation kit (Roche) following the manufacturer's instructions. First strand fluoresceinlabeled oligo(dT)-primed cDNA synthesis was performed using the Fluorescence Differential Display kit (Takara), according to the manufacturer protocol.

\section{PCR amplification}

Twenty-four PCR reactions were performed with three anchored fluorescein-labeled oligo (dT) primers (Takara) combined with eight random primers (HAP1-8; Kig and Temizkan, 2009). A volume of $2 \mu \mathrm{L}$ cDNA template was used directly in a $20-\mu \mathrm{L}$ reaction mixture containing 1X LA PCR buffer II, $0.1 \mathrm{mM}$ dNTP mix, $1.3 \mathrm{mM} \mathrm{MgCl}_{2,0.2 \mathrm{ULA}}$ Taq DNA polymerase (Takara), $0.5 \mu \mathrm{M}$ random primer and $0.3 \mu \mathrm{M}$ of the same anchored flourescein-labeled oligo(dT) primer used in first strand cDNA synthesis. After an initial $2 \mathrm{~min}$ of denaturation at $94^{\circ} \mathrm{C}, 40 \mathrm{amplifica}-$ tion cycles were performed as follows: $30 \mathrm{~s}$ at $94^{\circ} \mathrm{C}, 2 \mathrm{~min}$ at $38^{\circ} \mathrm{C}$, and $1 \mathrm{~min}$ at $72^{\circ} \mathrm{C}$. This was followed by $5 \mathrm{~min}$ final extension at $72^{\circ} \mathrm{C}$, and the reaction mix stored at $4^{\circ} \mathrm{C}$.

\section{Electrophoresis and silver staining}

PCR products were separated on $6 \%$ non-denaturing polyacrylamide gels $(16.5 \mathrm{~cm}$ x $28.0 \mathrm{~cm} \times 0.75 \mathrm{~mm}$ ). The gels were pre-run for $30 \mathrm{~min}$ prior to loading, and electrophoresis was performed in $1 \mathrm{XTBE}$ buffer at $8 \mathrm{~W}$ for $15 \mathrm{~h}$. cDNA bands were visualized by silver 
staining as described by Waterborg (2002).

\section{Recovery and reamplification}

Bands of interest were cut out and DNA fragments from polyacrylamide gels were recovered as described by QIAEX-II. Eluted DNA was re-amplified under identical conditions as in the initial PCR (except that 35 cycles were performed) with the corresponding oligo (dT) and random primer sets. PCR products were checked on $2 \%$ agarose gels and then purified with the High Pure PCR Product Purification kit (Roche).

\section{Sequence analysis}

Re-amplified PCR products were sequenced using the corresponding HAP primers. The sequencing was performed commercially (Refgen Ltd., Turkey), on an ABI 3130XL Genetic Analyzer using the BigDye Cycle Sequencing kit v3.1 (Applied Biosystems). Sequence data were subjected to BLASTX (Swiss-Prot) and BLASTN (RefSeq mRNA) searches of the $S$. pombe genome database at the National Center for Biotechnology Information (NCBI; http:// www.ncbi.nlm.nih.gov/). BLAST hits with $E$ value less than $10^{-4}$ and with bit score greater than 50 (for BLASTX) or 100 (for BLASTN) were considered significant.

\section{Real-time PCR}

Quantitativereal-timePCR was performed with the Mx3005Psystem(Stratagene), using theFastStartSYBR Green Masterkit(Roche). The gene-specific primersusedwere (act1:Forward 5'-ACTATGTATCCCGGTATTGCC-3', Reverse 5'-GACAGAGTATTTACGCTCAGG-3'; rpl302: Forward 5'- F: ATGATGCCAAGAATGCTTCC-3', Reverse 5'-AGTGGCACCA TTCAACATGA-3'; mpg1: Forward 5'-F:CGACCTTGAGGGTTATTGGA-3', Reverse 5'-ACTAGCTGGGGCCAAGATTT-3'). The synthetic first-strand cDNA used as template was synthesized with following manufacturer instructions: The reaction mixtures consisting of 25 $\mathrm{mL}$ FastStart SYBR Green Master, forward and reverse primers $(0.2 \mu \mathrm{M}$ each) and $0.1 \mu \mathrm{g}$ cDNA were made up to $50 \mu \mathrm{L}$ with ultra-pure nuclease-free water. The PCR conditions were set as follows: $95^{\circ} \mathrm{C}$ for $10 \mathrm{~min}$ (pre-incubation), followed by 40 cycles of $95^{\circ} \mathrm{C}$ for $10 \mathrm{~s}, 53^{\circ} \mathrm{C}$ for $10 \mathrm{~s}$, and $72^{\circ} \mathrm{C}$ for $20 \mathrm{~s}$. The final step included a gradual temperature increase from $55^{\circ} \mathrm{C}$ to $95^{\circ} \mathrm{C}$ at a rate of $1{ }^{\circ} \mathrm{C} / 10 \mathrm{~s}$ to enable melting curve data collection. A non-template control was run and serial dilutions $(1,1: 10$ and 1:100) of the reference (actin gene, act 1$)$ and the target genes were included in every assay. Amplification specificity of each reaction was verified by melting curve analysis. Expression levels were normalized against the reference gene, act1. Relative gene expression levels were determined according to the method of Pfaffle (2001).

\section{RESULTS AND DISCUSSION}

It is known that calorie restriction increases tolerance against oxidative stress and life span in S. pombe (Lin et al., 2000; Madrid et al., 2004; Roux et al., 2010). The increased resistance to oxidative stress, caused by glucose depletion (Madrid et al., 2004), gives rise to either carbon stress or accumulation of reactive oxygen species, which promotes aerobic respiration (Roux et al., 2009). 
Because ird11 is resistant to glucose repression (Kig et al., 2005) and to oxidative stress, differing from that caused by glucose deprivation, which triggers aerobic metabolism (Palabiyik et al., in press), it indicates that this mutant may provide a convenient tool to use in studies related to glucose sensing/signaling and oxidative stress.

In this study, we screened for genes whose expression decreased or increased upon exposure to mild oxidative stress in ird11 and wild-type, using the differential display technique. We isolated 17 different fragments from polyacrylamide gels. Two of them were sequenced and subjected to BLAST searches. According to $S$. pombe genome database query, we found that these sequences belong to the genes of rpl302 (SPAPB8E5.06c), encoding 60S ribosomal protein L3 (Liebich et al., 1994), and mpg1 (SPCC1906.01), encoding mannose-1-phosphate guanyltransferase. Ribosomal protein L3 is a member of a general gene expression system, and there are numerous ribosomal proteins displaying a unique promoter type in $S$. pombe (Gross and Käufer, 1998; Gasch, 2007). Mannose-1-phosphate guanyltransferase is an essential protein that is involved in glycosylation of cell wall proteins (Kukuruzinska et al., 1987; Huang and Snider 1995; Warit et al., 2000), and is required for the formation of a correct septum structure and in cell growth (Donoso et al., 2005). In addition, $m p g 1$ is a conserved gene from fungi to higher eukaryotes (Donoso et al., 2005)

Differentially expressed genes were confirmed by quantitative real-time PCR using genespecific primer sets. It was shown that expression profiles of rpl302 and $\mathrm{mpg} 1$ genes in quantitative real-time PCR were parallel to band intensities of these genes observed on polyacrylamide gels. The mpgl expression seemed to be similar in $\mathrm{H}_{2} \mathrm{O}_{2}$-treated $i r d 11$ and wild-type (Figure 1).
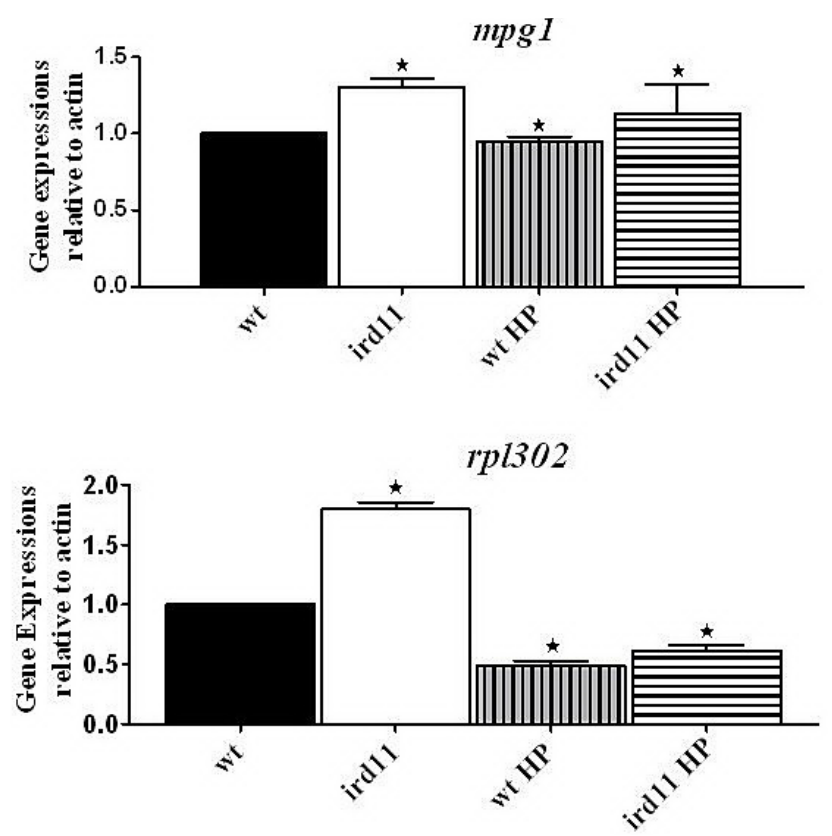

Figure 1. Expression levels of rpl302 and $\mathrm{mpg} 1$ genes relative to actl gene. The expression levels of the $r p l 302$ and mpgl genes in treated wild-type and ird11 (wt HP and ird11 HP) and un-treated cells (wt and ird11) were determined according to the Pfaffl method relative to actin gene. Un-treated wild type (wt) was used as a calibrator. Significant differences between calibrator (wt) and other cells (ird11, wt HP and ird11HP) were evaluated by Student's $t$-test. $* \mathrm{P}<0.05$. (wt: wild type, HP: treated with $\mathrm{H}_{2} \mathrm{O}_{2}$ ). 
Because ribosomal protein L3 is a member of a general gene expression system (Gasch, 2007), we estimated that the expression level of rpl302 gene under stressed conditions was decreased. In addition, as expected, the expression level of $r p l 302$ gene in $\mathrm{H}_{2} \mathrm{O}_{2}$-treated ird11 and wild-type cells was found to be lower than that of un-treated wild type $(0.6$ and 0.5 times, respectively). This indicated that the expression level of rpl302 gene was sharply reduced in both cells under stressed conditions. Although the ribosomal protein genes are among the most tightly co-regulated genes in the yeast genome (Gasch et al., 2000; Causton et al., 2001), interestingly, rpl302 expression in un-treated ird11 was found to be increased 1.8 fold compared to un-treated wild-type (Figure 1). Similarly, the expression level of the $\mathrm{mpg} 1$ gene in un-treated ird11 was found to be statistically higher (1.3 times) compared to that of wildtype. These findings suggest that both genes may play a role in the oxidative stress tolerance in ird11. The findings obtained from this study provided additional evidence which may be used in a convenient model cell for studies on glucose sensing/signaling and the oxidative stress response pathways.

\section{ACKNOWLEDGMENTS}

Research supported by Istanbul University Research Fund (project \#BAP1477 and \#4152). We thank Dr. Cenk Kig, from the Department of Molecular Cell Biology, Catholic University of Leuven, Belgium, for the gift of the arbitrary primers.

\section{REFERENCES}

Causton HC, Ren B, Koh SS, Harbison CT, et al. (2001). Remodeling of yeast genome expression in response to environmental changes. Mol. Biol. Cell 12: 323-337.

Chen D, Toone WM, Mata J, Lyne R, et al. (2003). Global transcriptional responses of fission yeast to environmental stress. Mol. Biol. Cell 14: 214-229.

Chen D, Wilkinson CR, Watt S, Penkett CJ, et al. (2008). Multiple pathways differentially regulate global oxidative stress responses in fission yeast. Mol. Biol. Cell 19: 308-317.

Donoso I, Munoz-Centeno MC, Sanchez-Duran MA, Flores A, et al. (2005). Mpg1, a fission yeast protein required for proper septum structure, is involved in cell cycle progression through cell-size checkpoint. Mol. Genet. Genomics 274: 155-167.

Flores CL, Rodriguez C, Petit T and Gancedo C (2000). Carbohydrate and energy-yielding metabolism in non-conventional yeasts. FEMS Microbiol. Rev. 24: 507-529.

Gancedo JM (2008). The early steps of glucose signalling in yeast. FEMS Microbiol. Rev. 32: 673-704.

Gasch AP (2007). Comparative genomics of the environmental stress response in ascomycete fungi. Yeast 24: 961-976.

Gasch AP, Spellman PT, Kao CM, Carmel-Harel O, et al. (2000). Genomic expression programs in the response of yeast cells to environmental changes. Mol. Biol. Cell 11: 4241-4257.

Gross T and Käufer NF (1998). Cytoplasmic ribosomal protein genes of the fission yeast Schizosaccharomyces pombe display a unique promoter type: a suggestion for nomenclature of cytoplasmic ribosomal proteins in databases. Nucleic Acids Res. 26: 3319-3322.

Gutz H, Heslot H, Leupold U and Loprieno N (1974). Schizosaccharomyces Pombe. In: Handbook of Genetics (King RC, ed.). Plenum Press, New York, 395-446.

Hoffman CS (2005). Glucose sensing via the protein kinase A pathway in Schizosaccharomyces pombe. Biochem. Soc. Trans. 33: 257-260.

Huang KM and Snider MD (1995). Isolation of protein glycosylation mutants in the fission yeast Schizosaccharomyces pombe. Mol. Biol. Cell 6: 485-496.

Ikner A and Shiozaki K (2005). Yeast signaling pathways in the oxidative stress response. Mutat. Res. 569: 13-27.

Janoo RT, Neely LA, Braun BR, Whitehall SK, et al. (2001). Transcriptional regulators of the Schizosaccharomyces pombe fbp 1 gene include two redundant Tuplp-like corepressors and the CCAAT binding factor activation complex. 
Genetics 157: 1205-1215.

Johnston M (1999). Feasting, fasting and fermenting. Glucose sensing in yeast and other cells. Trends Genet. 15: 29-33.

Kig C and Temizkan G (2009). Nitric oxide as a signaling molecule in the fission yeast Schizosaccharomyces pombe. Protoplasma 238: 59-66.

Kig C, Turkel S and Temizkan G (2005). Isolation and characterization of glucose derepressed invertase mutants from Schizosaccharomyces pombe. Biosci. Biotechnol. Biochem. 69: 2475-2478.

Kim SJ, Cho NC, Ryu IW, Kim K, et al. (2006). Carbon source-dependent regulation of the Schizosaccharomyces pombe pbh1 gene. J. Microbiol. 44: 689-693.

Kukuruzinska MA, Bergh ML and Jackson BJ (1987). Protein glycosylation in yeast. Annu. Rev. Biochem. 56: 915-944.

Liang P and Pardee AB (1992). Differential display of eukaryotic messenger RNA by means of the polymerase chain reaction. Science 257: 967-971.

Liebich I, Kohler G, Witt I, Gross T, et al. (1994). Two genes encoding ribosomal protein L3 of Schizosaccharomyces pombe and their proximal promoter regions. Gene 142: 119-122.

Lin SJ, Defossez PA and Guarente L (2000). Requirement of NAD and SIR2 for life-span extension by calorie restriction in Saccharomyces cerevisiae. Science 289: 2126-2128.

Madrid M, Soto T, Franco A, Paredes V, et al. (2004). A cooperative role for Atf1 and Pap1 in the detoxification of the oxidative stress induced by glucose deprivation in Schizosaccharomyces pombe. J. Biol. Chem. 279: 41594-41602.

Moradas-Ferreira P, Costa V, Piper P and Mager W (1996). The molecular defences against reactive oxygen species in yeast. Mol. Microbiol. 19: 651-658.

Palabiyik B, Kig C, Pekmez M, Dalyan L, et al. (2011). Investigation of the Relationship between Oxidative Stress and Glucose Signalling in Schizosaccharomyces pombe. Biochem. Genet.

Pekmez M, Arda N, Hamad I, Kig C, et al. (2008). Hydrogen peroxide-induced oxidative damages in Schizosaccharomyces pombe. Biologia 63: 151-155.

Pfaffl MW (2001). A new mathematical model for relative quantification in real-time RT-PCR. Nucleic Acids Res. 29 : e45.

Quinn J, Findlay VJ, Dawson K, Millar JB, et al. (2002). Distinct regulatory proteins control the graded transcriptional response to increasing $\mathrm{H}_{2} \mathrm{O}_{2}$ levels in fission yeast Schizosaccharomyces pombe. Mol. Biol. Cell 13: 805-816.

Rincon AM, Codon AC, Castrejon F and Benitez T (2001). Improved properties of baker's yeast mutants resistant to 2-deoxy-D-glucose. Appl. Environ. Microbiol. 67: 4279-4285.

Rolland F, Winderickx J and Thevelein JM (2001). Glucose-sensing mechanisms in eukaryotic cells. Trends Biochem. Sci. 26: 310-317.

Roux AE, Leroux A, Alaamery MA, Hoffman CS, et al. (2009). Pro-aging effects of glucose signaling through a G protein-coupled glucose receptor in fission yeast. PLoS Genet. 5: e1000408.

Roux AE, Arseneault G, Chartrand P, Ferbeyre G, et al. (2010). A screen for genes involved in respiration control and longevity in Schizosaccharomyces pombe. Ann N. Y. Acad. Sci. 1197: 19-27.

Schmidt MW, Houseman A, Ivanov AR and Wolf DA (2007). Comparative proteomic and transcriptomic profiling of the fission yeast Schizosaccharomyces pombe. Mol. Syst. Biol. 3: 79.

Toone WM, Morgan BA and Jones N (2001). Redox control of AP-1-like factors in yeast and beyond. Oncogene 20: 2336-2346.

Voet D, Voet GJ and Pratt WC (1999). Fundamentals of Biochemistry. John Wiley and Sons, New York, 195-219.

Warit S, Zhang N, Short A, Walmsley RM, et al. (2000). Glycosylation deficiency phenotypes resulting from depletion of GDP-mannose pyrophosphorylase in two yeast species. Mol. Microbiol. 36: 1156-1166.

Waterborg JH (2002). The Protein Protocols Handbook. 2nd edn. (Wolker JM, ed.). Humana Press Inch., Totowa.

Welton RM and Hoffmann CS (2000). Glucose monitoring in fission yeast via the Gpa2 go, the git5 G $\boldsymbol{\beta}$ and the git3 putative glucose receptor. Genetics 156: 513-521.

Zuin A, Carmona M, Morales-Ivorra I, Gabrielli N, et al. (2010). Lifespan extension by calorie restriction relies on the Sty1 MAP kinase stress pathway. EMBO J. 29: 981-991. 